\title{
Prevalence and associated metabolic factors for thyroid nodules: a cross- sectional study in Southwest of China with more than 120 thousand populations
}

\author{
$\mathrm{Li} \mathrm{Xu}^{1+}$, Fanling Zeng ${ }^{1+}$, Yutong Wang ${ }^{2}, \mathrm{Ye} \mathrm{Bai}^{3}$, Xuefeng Shan ${ }^{4^{*}}$ and Lingxi Kong ${ }^{4^{*}}$
}

\begin{abstract}
Objective: To explore the prevalence and its associated metabolic factors of thyroid nodules (TNs) among subjects who participated in the physical examinations in Chongqing, China.

Methods: The participants from the Health Management Center of JinShan Hospital of Chongqing Medical University, between September 2015 and May 2020, were included in this study. All of the participants underwent thyroid ultrasonography, anthropometric measurements, and serum examinations. Differences in the TNs prevalence were compared with the chi-square test or Wilcoxon rang-sum test. Multivariable logistic regression analyses were used to estimate the metabolic factors associated with TNs and multiple thyroid nodules (MTNs).

Results: Of the included 121,702 participants, 41,547 had TNs, and 20,899 had MTNs, with the prevalence of 34.1 and $17.0 \%$, respectively. Women had a significantly higher prevalence of TNs than men $\left(40.6 \%\right.$ vs. $29.8 \%$; $X^{2}=$ $1517.33, P<0.001)$, and TNs prevalence was gradually increased with age $(P$ for trend $<0.001)$. Female gender, advanced age, and metabolic factors including central obesity, hypertension, diabetes and fatty liver were positively associated with TNs; BMI, hyperlipoidemia and hyperuricemia were not independent risk factors of TNs. While female gender, advanced age, central obesity, hypertension and diabetes were independent risk factors of MTNs.

Conclusions: The prevalence of thyroid nodules was relatively high. The associated factors identified in this study could help the clinicians to detect the high-risk patients and make targeted screening strategies for the preventing of the occurrence of TNs.
\end{abstract}

Keywords: Thyroid nodules, Prevalence, Metabolic factors, Multiple thyroid nodules

\footnotetext{
*Correspondence: 83846674@qq.com; klingxi@126.com

${ }^{+} \mathrm{Li} \mathrm{XU}$ and Fanling Zeng are co-first authors.

${ }^{4}$ Department of Pharmacy, The First Affiliated Hospital of Chongqing Medical University, 400016 Chongqing, China

Full list of author information is available at the end of the article
}

C C The Author(s). 2021 Open Access This article is licensed under a Creative Commons Attribution 4.0 International License, which permits use, sharing, adaptation, distribution and reproduction in any medium or format, as long as you give appropriate credit to the original author(s) and the source, provide a link to the Creative Commons licence, and indicate if changes were made. The images or other third party material in this article are included in the article's Creative Commons licence, unless indicated otherwise in a credit line to the material. If material is not included in the article's Creative Commons licence and your intended use is not permitted by statutory regulation or exceeds the permitted use, you will need to obtain permission directly from the copyright holder. To view a copy of this licence, visit http://creativecommons.org/licenses/by/4.0/ The Creative Commons Public Domain Dedication waiver (http://creativecommons.org/publicdomain/zero/1.0/) applies to the data made available in this article, unless otherwise stated in a credit line to the data. 


\section{Background}

Thyroid nodules (TNs), one of the most common thyroid disease, has been defined as discrete lesions within the thyroid gland, radiologically distinct from surrounding thyroid parenchyma [1]. It is reported that the prevalence of TNs was about $22.7 \%$ in China, which may inflict a heavy disease burden on the patients [2]. However, due to the variations in the distributions of age, race and gender composition, and the relatively smaller sample size in previous studies, the reported TNs prevalence was not consistent, ranging from 10 to $50 \%$, which makes it difficult for drawing a conclusive conclusion [3-7].

TNs thyroid cancer occurs in approximately $7-15 \%$ of thyroid nodules [8]. However, most of the TNs patients are asymptomatic and the increased use of ultrasound (US) allows them to be diagnosed as early as possible. Having a better look at the associated factors for TNs may help the clinicians to identify the high-risk populations and provide preventive treatment and management with them. Previous studies showed metabolic factors, including obesity, hypertension, diabetes, dyslipidemia, and hyperuricemia, and fatty liver were associated with the risk of TNs, which provides opportunities for the identification of high-risk patients [9-14]. But researches based on large samples were still lacked, and the investigations were seldom conducted in China, which partly limited the application of these findings.

In the present study, we aimed to conduct a crosssectional study incorporating over 120 thousand population in Chongqing, China, to identify the prevalence and metabolic risk factors for TNs and multi thyroid nodules (MTNs).

\section{Subjects and methods Subjects}

Participants who participated in the physical examination in the Health Management Center of JinShan Hospital, the First Affiliated Hospital of Chongqing Medical University, between September 2015 and May 2020 were included. During this period, a total of 243,768 subjects underwent general physical examination. After excluding the subjects with multiple medical examinations and the ones: (1) did not receive thyroid ultrasound or abdominal ultrasound(US) examination; (2) people under 18 years old, pregnant or lactating women; (3) with a history of thyroid surgery or drug treatment with thyroid disease; 4)with cancer or other serious illness. In total, 121,702 subjects were included in the final analysis. Our research complies with the Declaration of Helsinki, and the protocol was approved by the Ethics Committee of The First Affiliated Hospital of Chongqing Medical University $(2020$ - 868). Informed consent has been obtained from each patient according to the requirements of the committee before data collection.

\section{Anthropometric parameters}

Collection of demographic information and medical histories as well as anthropometric examination of the subjects was completed by the trained nurses. Height $(\mathrm{m})$ and weight $(\mathrm{kg})$ was measured by a health analyzer (SK-X80). Body mass index (BMI) was calculated as weight/height ${ }^{2}$. Systolic blood pressure (SBP) and diastolic blood pressure (DBP) were measured in the sitting position with a wrist sphygmomanometer (HBP9020, Omron, Kyoto, Japan). The waist circumference (WC) was measured midway between the lowest ribs and the iliac crest with a folding tape according to the World Health Organization and International Diabetes Federation [15].

\section{Laboratory examination}

For each subject, venous blood samples were taken for laboratory examination after a fasting period of $8 \mathrm{~h}$. Fasting blood glucose (FBG) were detected by the hexokinase method and blood uric acid (UA) was detected by the uricase peroxidase method. Serum triglyceride (TG), total cholesterol (TC), low-density lipoprotein cholesterol (LDL-C), and high-density lipoprotein cholesterol (HDL-C) were detected by the enzymatic method. All the above measurements were done by using an automatic chemistry analyzer (Hitachi 7600, Hitachi Corporation, Tokyo, Japan). Reference ranges of the blood tests were listed as follows: $3.9-6.1 \mathrm{mmol} / \mathrm{L}$ for FBG,155-357 umol/L for UA, $2.80-5.20 \mathrm{mmol} / \mathrm{L}$ for $\mathrm{TG}, 0.35-1.70$ $\mathrm{mmol} / \mathrm{L}$ for $\mathrm{TC}, 2.07-3.10 \mathrm{mmol} / \mathrm{L}$ for $\mathrm{LDL}-\mathrm{C}$ and $0.90-1.80 \mathrm{mmol} / \mathrm{L}$ for HDL-C.

\section{Ultrasound Examination}

Thyroid Ultrasound Examination: All of the subjects with a supine position fully exposed the neck and then the thyroid ultrasound examination was performed by a specific thyroid sonographer using a 7-MHz linear transducer (PVT-705bt, Toshiba, Japan). For each nodule, size (length, width and depth), shape, location, echogenicity, boundary, and vascularity were collected and recorded.

Abdominal Ultrasound Examination: Abdominal ultrasound examination was performed by a professional sonographer using a 3.5-MHz specific transducer (PVT375bt, Toshiba, Japan).

\section{Definition of variables}

Thyroid Nodules (TNs): Thyroid nodules was diagnosed according to the 2011 version of thyroid imaging report and data system (TI-RADS) classification criteria for risk assessment of malignant thyroid nodules [16]. Single thyroid nodules (STNs) were defined as only one nodule on any side of thyroid, while multiple thyroid nodules (MTNs) were defined as two or more than two nodules in one or both sides of the thyroid [1]. 
Fatty Liver: Fatty liver was diagnosed with the US features as follows: (1) Diffuse enhancement of near-field echo of the liver (stronger than that in the kidney), gradual attenuation of the far-field echo; (2) unclear display of intrahepatic lacuna structure; (3) mild to moderate hepatomegaly; (4) unclear display of right lobe of liver and diaphragm [17].

Obesity: According to the Working Group on Obesity in China $[18,19]$, underweight, normal weight, overweight, and obesity were defined as $\mathrm{BMI}<18.5$, 18.5$23.9,24-27.9$, and $\geq 28$ respectively. Central obesity was defined as waist circumference $(\mathrm{WC}) \geq 85 \mathrm{~cm}$ for men and $\geq 80 \mathrm{~cm}$ for women.

Hypertension: SBP/DBP $\geq 140 / 90 \mathrm{~mm} \mathrm{Hg}(1 \mathrm{~mm} \mathrm{Hg}=$ $0.133 \mathrm{kPa}$ ) or patients having been diagnosed with hypertension and receiving treatment [20].

Glucose status: Normal blood glucose and impaired fasting glucose(IFG) were defined as FBG $<6.1$ mmoLand $6.1 \mathrm{mmol} / \mathrm{L} \leq \mathrm{FBG}<7.0 \mathrm{mmol} / \mathrm{L}$ respectively, according to the American Diabetes Association criteria [21]. Diabetes mellitus(DM) was defined as $\mathrm{FBG} \geq 7.0 \mathrm{mmol} / \mathrm{L}$ or under treatment of insulin or glucose-lowering drugs.

Dyslipidemia and Hyperuricemia: Dyslipidemia were classified as hypercholesterolemia $(\geq 5.2 \mathrm{mmol})$, hypertriglyceridemia $(\geq 1.7 \mathrm{mmol} / \mathrm{L})$, High LDL-C $(\geq 3.1 \mathrm{mmol} /$ $\mathrm{L})$ and low $\mathrm{HDL}-\mathrm{C}(<0.9 \mathrm{mmol} / \mathrm{L})$, and hyperuricemia was defined as uric acid (UA) $>428 \mathrm{umol} / \mathrm{L}$ for men and $\mathrm{UA}>357 \mathrm{umol} / \mathrm{L}$ for women respectively.

\section{Statistical Analysis}

The SPSS 22.0 software package (IBM, SPSS Inc., USA) was used for statistical analysis. Continuous data were described by mean \pm standard deviation (SD); categorical data were described by percentage and counts. Differences in the prevalence of TNs between different groups were evaluated by chi-square test or Wilcoxon rang-sum test. Differences of mean value among individuals with or without TNs were evaluated by unpaired t-test. Univariate binary logistic regression analysis was applied to assess the associations of metabolic factors and TNs and MTNs, respectively. The variables with $p$ value $<0.05$ were included in multivariable binary logistic regression analysis. All tests were two-tailed, and $p$ values $<0.05$ were considered of significant significance.

\section{Results}

\section{Baseline Features of General Population}

Of the included 121,702 subjects $(73,139$ were males and 48,563 were females), 41,547 were found to have TNs, with the prevalence of $34.1 \%$ (Table 1). Among those patients with TNs, STNs accounted for $49.7 \%$ ( $N=$ 20,648 ) of the patients, while MTNs accounted for $50.3 \%(N=20,899)$, with the prevalence of 17.0 and $17.2 \%$, respectively. The prevalence of TNs in women
(40.6\%, $N=19,734)$ was significantly higher than that in men $\quad(29.8 \%, \quad N=21,813) \quad\left(\chi^{2}=1517.33, \quad P<0.001\right)$ (Table 1). The mean age of all the subjects was $42.44 \pm$ 13.24 years, the age of those with TNs $(47.89 \pm 13.97$ years) was older than those without TNs $(39.62 \pm 11.90$ years) $(P<0.001)$ (Table 1$)$. There was a significant difference in age between TNs and those without TNs $\left(\mathrm{W}=1.10 \times 10^{9}, P<0.001\right)$ (Table 1). Furthermore, the prevalence of TNs was found to be increased with age ( $P$ for trend $<0.001)$. Of the 121,702 healthy subjects, mean BMI was $23.51 \pm 4.06 \mathrm{~kg} / \mathrm{m}^{2}$, mean $\mathrm{WC}$ was $81.37 \pm$ $9.95 \mathrm{~cm}$, mean SBP was $123.61 \pm 17.30 \mathrm{mmHg}$, mean DBP was $75.07 \pm 11.54 \mathrm{mmHg}$, mean $\mathrm{FBG}$ was $5.43 \pm$ $1.19 \mathrm{mmol} / \mathrm{L}$, mean $\mathrm{TC}$ was $4.91 \pm 0.94 \mathrm{mmol} / \mathrm{L}$, mean TG was $1.64 \pm 1.49 \mathrm{mmol} / \mathrm{L}$, mean $\mathrm{HDL}-\mathrm{C}$ was $1.40 \pm$ $0.34 \mathrm{mmol} / \mathrm{L}$, mean LDL-C was $2.96 \pm 0.81 \mathrm{mmol} / \mathrm{L}$ and mean UA was $350.32 \pm 95.51 \mu \mathrm{mol} / \mathrm{L}($ Table 1$)$. Compared with those without TNs, the individuals with TNs had a significantly higher level of BMI, WC, SBP, DBP, FBG, TC, TG, HDL-C and LDL-C $(P<0.001)$ (Table 1$)$.

\section{Association Between Metabolic Factors and TNs risk}

As shown in Table 2, the univariate binary logistic regression suggested BMI, central obesity, hypertension, higher blood glucose, hypercholesterolemia, hypertriglyceridemia, high level of LDL-C, hyperuricemia and fatty liver were all positively associated with TNs risk, while no association was found in HDL-C (Table 2). When stratified by gender of the participants, all of the metabolic factors, including HDL-C, were associated with the TNs risk (Table 2).

When incorporated all the factors into the multivariable logistic model, results suggested female gender, advanced age, central obesity, hypertension, diabetes, and fatty liver were independently associated with the risk of TNs in the general population (Fig. 1a ). These associations were not significantly changed after sub-grouped by the gender of the participants (Fig. 1b for male and Fig. 1c for female).

\section{Association Between Metabolic Factors and MTNs compared with STNs}

Univariate binary logistic regression analysis of data of 41,547 individuals with TNs indicated that overweight, central obesity, hypertension, high blood glucose, hypercholesterolemia, low level of HDL-C, high level of HDL$\mathrm{C}$, hyperuricemia, and fatty liver were all significantly associated with the of the prevalence of MTNs compared with STNs, while no association was found between higher TG level and MTNs(Table 3). All of these metabolic factors were associated with the MTNs in females, but for male, overweight, central obesity, hypertension, high blood glucose, low level of HDL-C, high level of LDL-C, and hyperuricemia were associated with the MTNs(Table 3). 
Table 1 Baseline features of general population $(N=121,702)$

\begin{tabular}{|c|c|c|c|c|c|}
\hline & Total & TNs & without TNs & $x^{2 / w / t}$ & $P$ value \\
\hline Total(\%) & 121,702 & $41,547(34.1)$ & $80,155(65.9)$ & & \\
\hline Female & 48,563 & 19,734(40.6) & 28,829(59.4) & 1517.33 & $<0.001$ \\
\hline Male & 73,139 & 21,813(29.8) & $51,326(70.2)$ & & \\
\hline Age (years) & $42.44 \pm 13.24$ & $47.89 \pm 13.97$ & $39.62 \pm 11.90$ & -102.924 & $<0.001$ \\
\hline \multicolumn{6}{|l|}{ Age(years,\%) } \\
\hline$\leq 30$ & 25,455 & 4912(19.3) & 20,543(80.7) & $1.10 \times 10^{9}$ & $<0.001$ \\
\hline $31-40$ & 35,672 & $8527(23.9)$ & $27,145(76.1)$ & & \\
\hline $41-50$ & 27,063 & $10,080(37.2)$ & $16,983(62.8)$ & & \\
\hline $51-60$ & 20,062 & $9845(49.1)$ & $10,217(50.9)$ & & \\
\hline$\geq 61$ & 13,450 & $8183(60.8)$ & $5267(39.2)$ & & \\
\hline $\operatorname{BMI}\left(\mathrm{Kg} / \mathrm{m}^{2}\right)$ & $23.51 \pm 4.06$ & $23.72 \pm 3.89$ & $23.40 \pm 4.15$ & -12.477 & $<0.001$ \\
\hline $\mathrm{WC}(\mathrm{cm})$ & $81.37 \pm 9.95$ & $81.87 \pm 9.83$ & $81.10 \pm 10.00$ & -12.234 & $<0.001$ \\
\hline SBP (mmHg) & $123.61 \pm 17.30$ & $126.36 \pm 18.58$ & $122.20 \pm 16.42$ & -36.724 & $<0.001$ \\
\hline $\mathrm{DBP}(\mathrm{mmHg})$ & $75.07 \pm 11.54$ & $76.26 \pm 11.84$ & $74.45 \pm 11.33$ & -24.5 & $<0.001$ \\
\hline FBG (mmol/L) & $5.43 \pm 1.19$ & $5.57 \pm 1.35$ & $5.36 \pm 1.10$ & -26.95 & $<0.001$ \\
\hline $\mathrm{TC}(\mathrm{mmol} / \mathrm{L})$ & $4.91 \pm 0.94$ & $4.99 \pm 0.95$ & $4.87 \pm 0.93$ & -20.69 & $<0.001$ \\
\hline $\mathrm{TG}(\mathrm{mmol} / \mathrm{L})$ & $1.64 \pm 1.49$ & $1.66 \pm 1.48$ & $1.63 \pm 1.49$ & -2.71 & $<0.001$ \\
\hline $\mathrm{HDL}-\mathrm{C}(\mathrm{mmol} / \mathrm{L})$ & $1.40 \pm 0.34$ & $1.42 \pm 0.35$ & $1.39 \pm 0.34$ & -12.8 & $<0.001$ \\
\hline LDL-C(mmol/L) & $2.96 \pm 0.81$ & $3.01 \pm 0.82$ & $2.93 \pm 0.81$ & -15.18 & $<0.001$ \\
\hline $\mathrm{UA}(\mu \mathrm{mol} / \mathrm{L})$ & $350.32 \pm 95.51$ & $340.72 \pm 93.52$ & $355.26 \pm 96.15$ & 25.21 & $<0.001$ \\
\hline Female & $279.92 \pm 62.28$ & $283.38 \pm 64.73$ & $277.57 \pm 60.45$ & -9.827 & $<0.001$ \\
\hline Male & $396.3 \pm 84.83$ & $391.6 \pm 85.34$ & $398.29 \pm 84.53$ & 9.71 & $<0.001$ \\
\hline \multicolumn{6}{|l|}{ Fatty Liver } \\
\hline No & 84,098 & $27,696(32.9)$ & $56,402(67.1)$ & 146.61 & $<0.001$ \\
\hline Yes & 33,976 & $12,442(36.7)$ & $21,534(63.3)$ & & \\
\hline
\end{tabular}

TNs thyroid nodules; BMI body mass index; WC waist circumference; SBP systolic blood pressure; DBP diastolic blood pressure; FBG fasting blood glucose; TC total cholesterol; TG triglycerides; $L D L-C$ low-density lipoprotein cholesterol; HDL-C high-density lipoprotein cholesterol; UA uric acid

Multivariable binary logistic regression analysis showed that in the general population, female gender, advanced age, central obesity, hypertension and diabetes were independent risk factors of MTNs after adjusting for BMI, level of blood lipids, level of uric acid and fatty liver (Fig. 2a). After stratified by the sex of the participants, advanced age, central obesity, hypertension and diabetes were also associated with the MTNs risk in men, while for female, only advanced age and hypertension were associated with MTNs risk (Fig. $2 b$ for male and Fig. 2c for female)

\section{Discussion}

Thyroid nodule is highly prevalent and is one of the rapidly increasing diseases worldwide. The present study suggested that the prevalence of TNs in Chongqing was $34.1 \%$, which was lower than the rate reported from the studies in North America (67\%) [22], similar to Germany (33\%) [23] and Kora (34.2\%) [24], and was higher than that in Mexico (19.6\%) [25]. The variations in the TNs prevalence also existed in different regions, even within the same country. During the past ten years, a series of studies tried to investigate the TNs prevalence in China, and a systematic review and meta-analysis also suggested the overall TNs prevalence in China was about $22.7 \%$ [2]. However, studies were seldom conducted in Chongqing city and did not incorporate into previous analyses. The present study suggested the TNs prevalence in Chongqing was relatively higher than the prevalence rate in Guizhou (10.12\%) [26] and Liaoning $(10.17 \sim 12.64 \%)$ [27], similar to that in Shandong (31.56\%) [28] and Guangdong (31.65\%) [29], but it was relatively lower than that in Beijing (58.69\%) [30] and Nanjing (46.6\%) [12]. The difference of TNs prevalence between our study and those conducted in the other areas of China may be explained by the difference of lifestyle and dietary habit. Additionally, the prevalence in this study was similar to a recent study reported in Chongqing city, with the prevalence of $32.4 \%$ [31]. Moreover, we also found that the prevalence of MTNs 


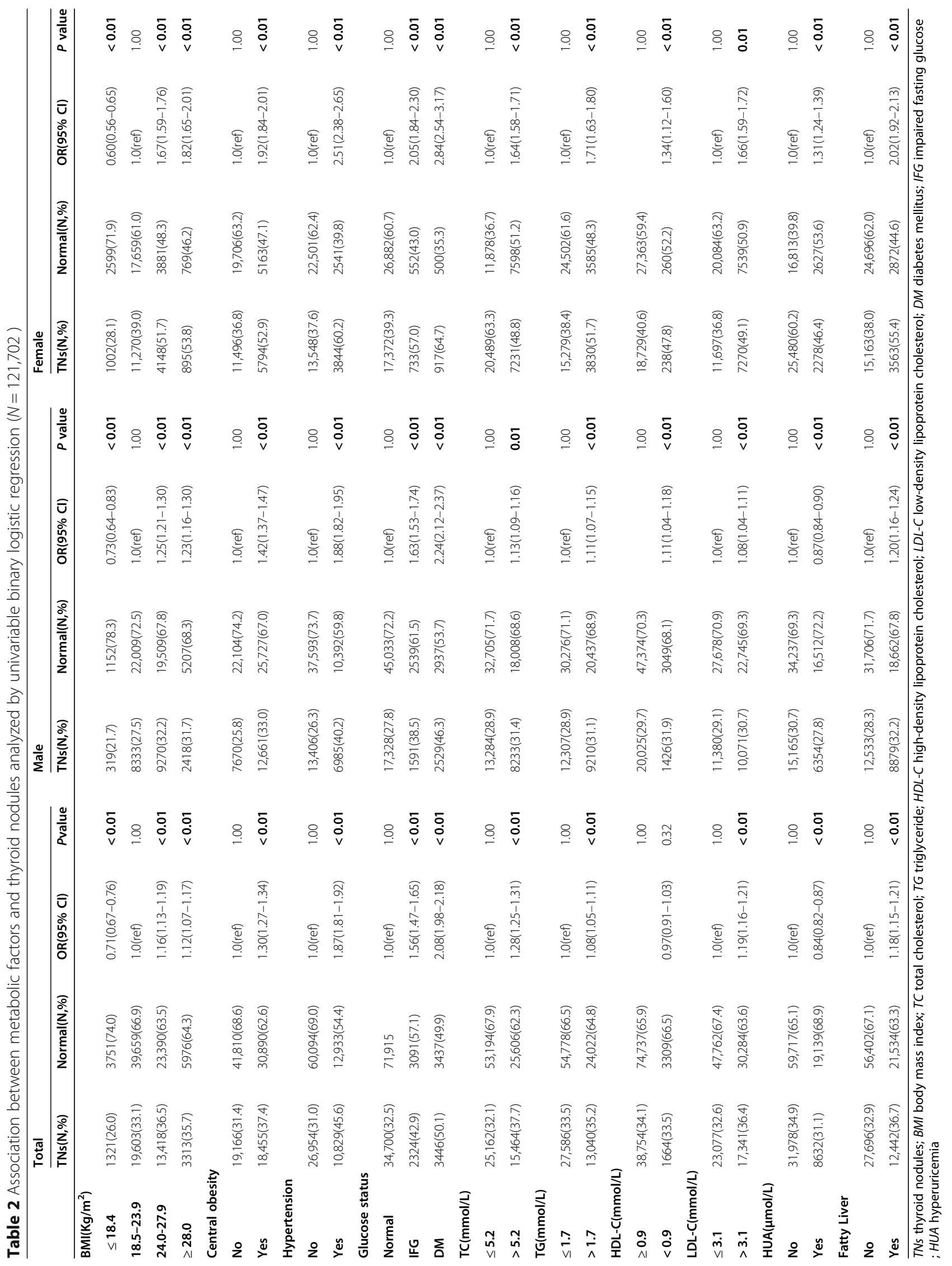




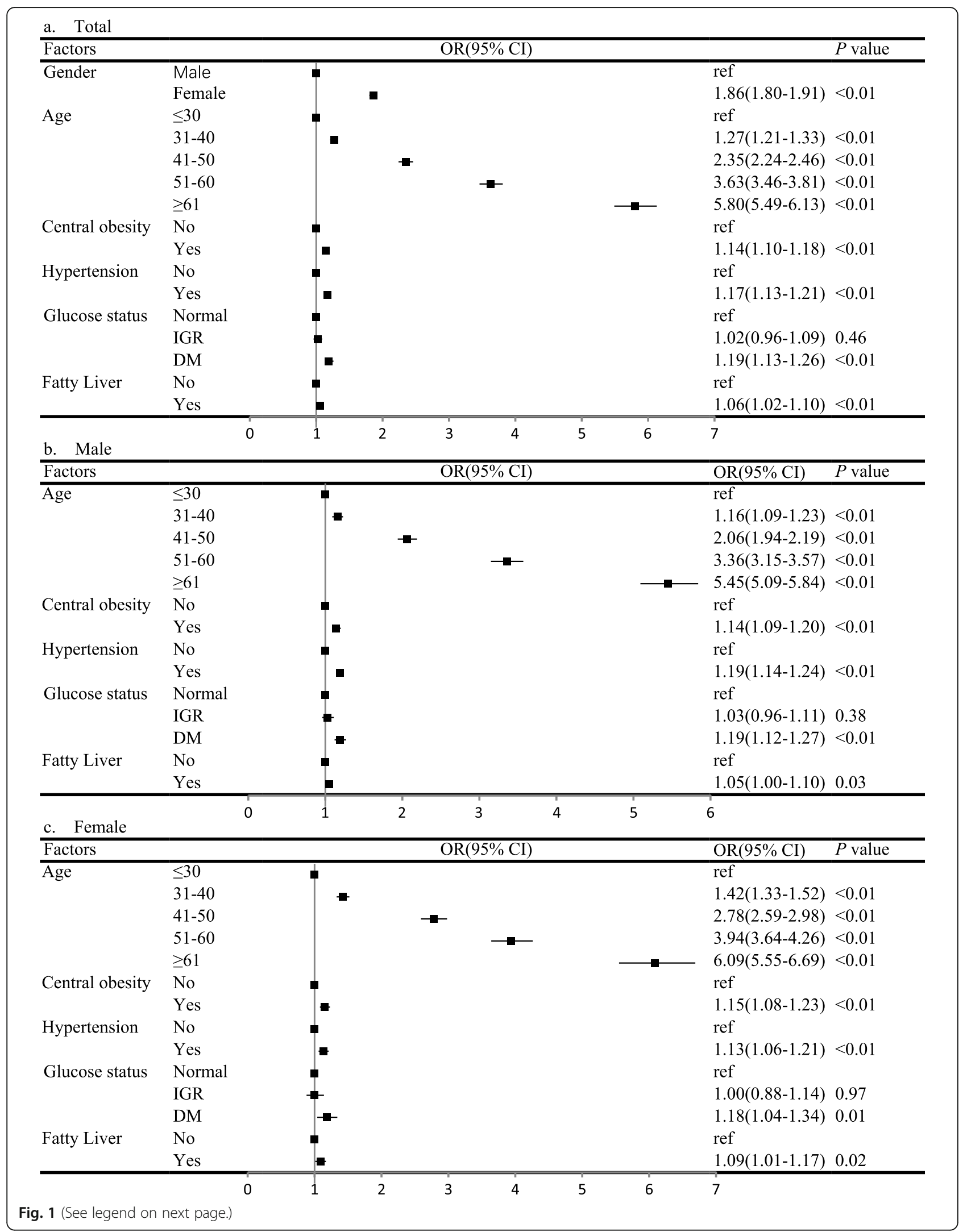


(See figure on previous page.)

Fig. 1 Independent risk factors of thyroid nodules analyzed by multivariate binary logistic regression( $N=121,702)$, adjusted for $B M I, T C$, TG, HDL-C, LDL-C and HUA. a: total population; b: male population; c: female population. BMI: body mass index; TC: total cholesterol; TG: triglyceride; HDL-C: high-density lipoprotein cholesterol; LDL-C: low-density lipoprotein cholesterol; DM: diabetes mellitus; IFG: impaired fasting glucose;

HUA: hyperuricemia

was about $17.0 \%$, accounted for $50.3 \%$ of the total TNs patients, which is also consistent with the result reported by Liu colleagues [14].

Results of the present study showed that female gender, advanced age and metabolic factors, including central obesity, hypertension, diabetes and fatty liver, were positively associated with the risk of TNs.

Female gender and age have long been proved to be the risk factors of TNs $[2,24,30,32]$. The gender differences in TNs may be attributed to physiology, pregnancy, and estrogen exposure of female [33]. Estrogen is a substance that promotes the growth of thyroid stem cells and progenitor cells, which contributes to the proliferation of thyroid stem cells through classical genomic and non-genomic pathways and leads to the occurrence of TNs $[34,35]$. The results of the present study proved that female population are more likely to be diagnosed with TNs and prevalence of TNs in women and man is $40.6 \%$ vs. $29.8 \%$, which is similar to that of a study in Shanxi [14]. Increasing age of population is another cause of the high prevalence of TNs, and currently researchers believe that reactive oxygen free radicals precipitate with the rise of age, leading to changes in thyroid tissue and the accumulation of harmful changes in cells [36]. Furthermore, hyperplasia of fibrous connective tissue, inflammatory infiltration, and filtration in the interstitium of thyroid tissue, and vacuolation of the cytoplasm of the vesicle cells eventually result in the formation of nodules in the thyroid tissue [37]. It has been found in our study that the prevalence of TNs increased with age, and the occurrence of TNs reached a high level of $60.8 \%$ in people at the age over 60 years. In other words, ultrasound examination of the thyroid in heath checkups should be highlighted, especially in elder female people.

Strong correlations between body weight, BMI, obesity, waist circumference, and thyroid nodules have been confirmed by some previous studies $[8,11,14,24,38$, 39]. It has been reported that the relationship between obesity and thyroid nodules is probably related to leptin secreted by adipose tissue [40]. The increase of serum leptin concentration in the obesity population can promote the rise of thyroid-stimulating hormone levels, which leads to the occurrence and development of thyroid nodules [40]. Results of the present study showed a higher prevalence of TNs in the group of central obesity, and we noticed that in our results BMI of the populations with TNs was higher than that of those without
TNs, however, it was not an independent risk factor of thyroid nodules after adjustment. The association between BMI and TNs may depend on different thyroid functions and population grouping methods, which would require further studies for illumination.

Hypertension has been found to be a risk factor of TNs and blood pressure level has been proved to be positively correlated with serum thyroid-stimulating hormone level, which could further increase the prevalence of thyroid nodules [41, 42]. According to previous researches, diabetes might also be related to TNs risk [41] and it has been found that the prevalence of TNs was significantly higher in patients with insulin resistance(IR) than those without IR [43].IR has been reported as an independent risk factor for increased thyroid volume and nodule prevalence, however the exact molecular mechanisms and the pathophysiology were not exactly understood [44-46].It was inferred that IR might cause the proliferation of thyroid cells and promote the formation of nodules and the progression of carcinoma [45]. Additionally, Jornayvaz et al. [47] has found that increase of body fat can be caused by insulin resistance, and with the accumulating and entering of excessive fatty acids in liver, fatty liver forms. Therefore, the onset of fatty liver is related to insulin resistance and fatty liver may be correlated with thyroid nodules through IR. The above findings may explain the higher prevalence of TNs in groups with hypertension, diabetes, and fatty liver in the present study. And it also reminds us that people with hypertension, diabetes and fatty liver should attach high awareness to the occurrence of TNs.

As for the correlation between hyperlipoidemia, uric acid and thyroid nodules, results of our studies proved that they were not independent risk factors of TNs, which was different from that of some previous researchers [9, 14, 32]. Zou et al. [32] reported that high LDL-C was more likely to be associated with MTNs and Yin et al. [9] revealed that elevated triglycerides was a risk factor for TNs, but our data was not consistent with it. In addition, uric acid levels was not associated with the prevalence of TNs after multiple adjustment, which was not in agreement with the results of Liu colleagues [14]. The difference may be possibly explained by the difference of the research subjects enrolled in and the small size of the samples. We believed that more evidence should be needed to clarify the influence of lipids levels and uric acid on TNs. 


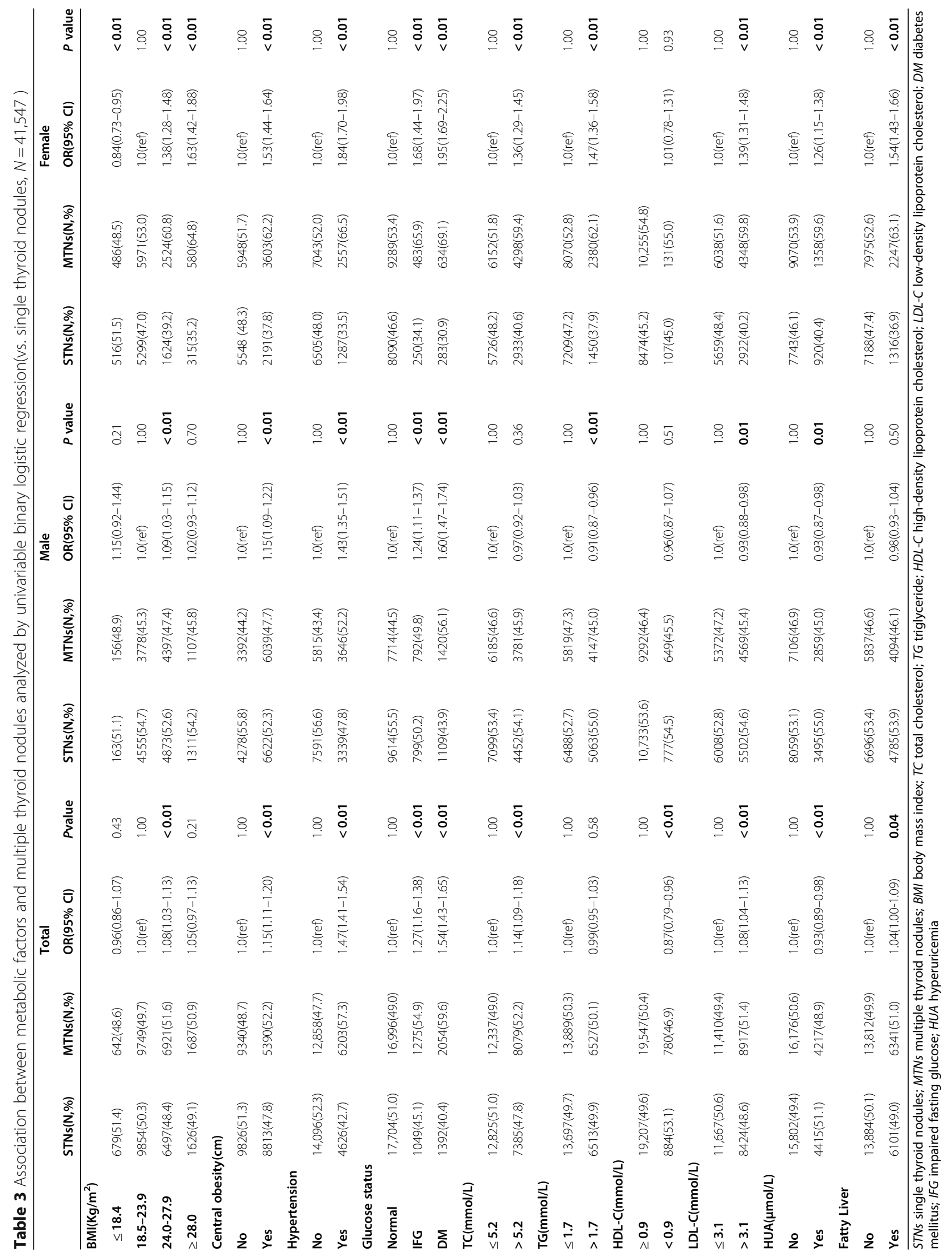




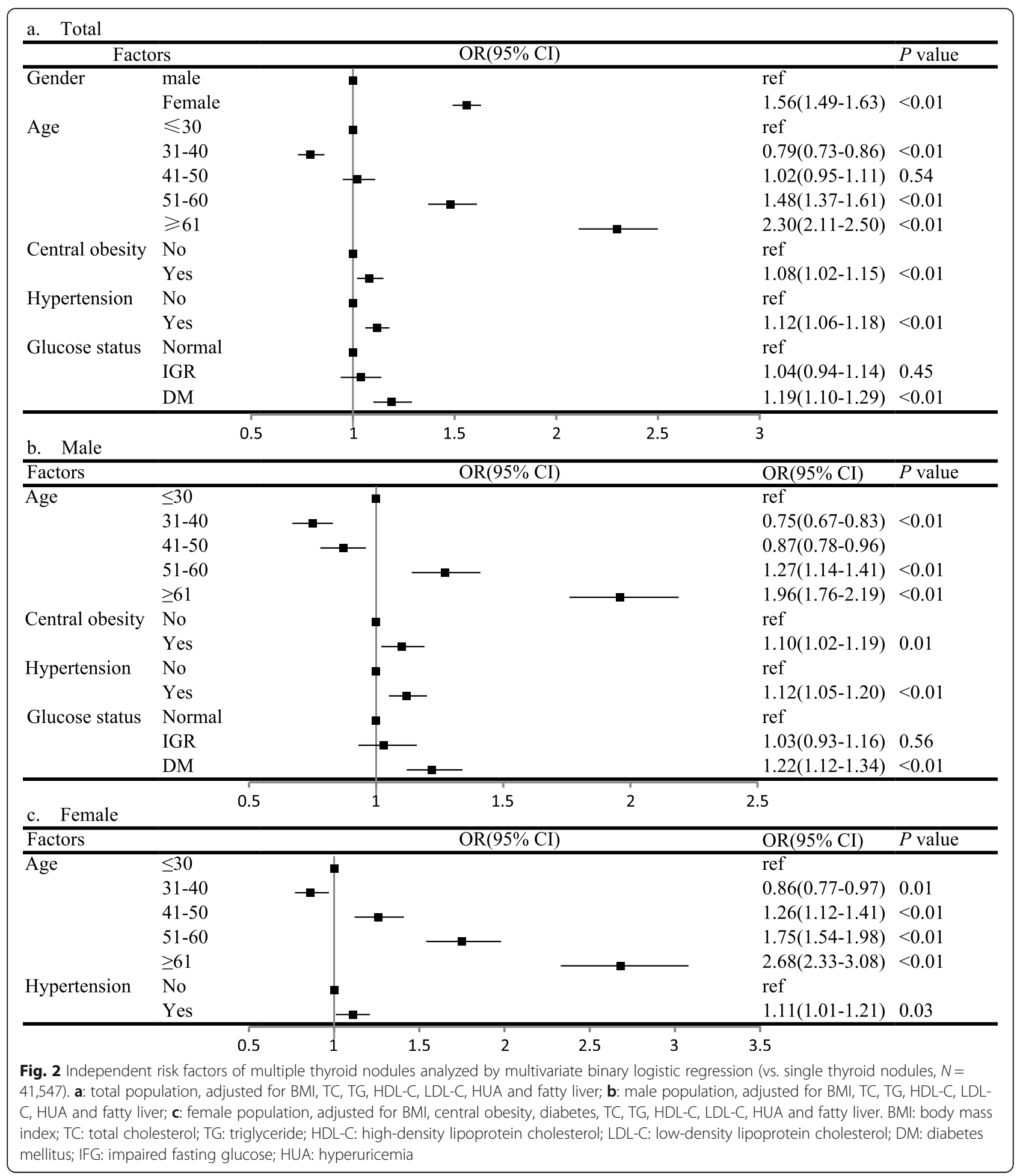

Besides, the results of the analysis for MTNs indicated that female gender, increasing age, central obesity, hypertension, and diabetes are independent risk factors of MTNs in the general population compared with STNs. When stratified by sex, for men, increasing age, central obesity, hypertension and diabetes are highly associated with the occurrence of MTNs; for women, increasing age and hypertension are independent risk factors of MTNs compared with STNs. Our results suggests that men with central obesity and diabetes should pay more attention to in the diagnosis of MTNs compared with women. 


\section{Conclusions}

The present study showed the prevalence of TNs in Chongqing city was as high as $34.1 \%$. Female gender, advanced age, central obesity, hypertension, diabetes and fatty liver were independent risk factors of TNs, which provides us clues to identify the high-risk patients by a targeted screening strategy of conducting thyroid ultrasonography among women, the elder subjects and those with central obesity, hypertension, diabetes and fatty liver.

\section{Abbreviations}

STNs: Single thyroid nodules; MTNs: Multiple thyroid nodules; TNs: Thyroid nodules; BMI: Body mass index; WC: Waist circumference; FBG: Fasting blood glucose; IFG: impaired fasting glucose; TG: Triglyceride; TC: Total cholesterol; LDL-C: Low-density lipoprotein cholesterol; HDL-C: High-density lipoprotein cholesterol; US: Ultrasound; UA: Uric acid; TI-RADS: Thyroid imaging reporting and data system; IGR: Impaired glucose regulation; IFG: Impaired fasting blood glucose; DM: Diabetes; IR: Insulin resistance

\section{Acknowledgements}

We would like to acknowledge Xin Wang (Sichuan University) who reviewed the article for professional and grammatical errors.

\section{Authors' contributions}

Li Xu and Fanling Zeng conceptualized and designed the study. Lingxi kong and XueFeng Shan collected and assembled the data. Yutong Wang and Ye Bai analyzed and interpreted the data. Lingxi Kong and XueFeng Shan wrote the manuscript. Li Xu and Fanling Zeng guided the writing and modification of the manuscript. All authors read and approved the final version of the manuscript.

\section{Funding}

This study was founded by the National Natural Science Foundation of China (8190112724).

\section{Availability of data and materials}

The datasets used and analyzed during the current study available from the corresponding author on reasonable request.

\section{Declarations}

\section{Ethics approval and consent to participate}

The present study was approved by the Ethics Committee of The First Affiliated Hospital of ChongQing Medical University (2020 - 868) and informed consent has been obtained from each patient according to the requirements of the committee before data collection. All the procedures complied with the Declaration of Helsinki and its later amendments or comparable ethical standards.

\section{Consent to publication}

Not applicable.

\section{Competing interests}

All the authors declare that they have no conflict of interests.

\section{Author details}

${ }^{1}$ Health Management Centre, The First Affiliated Hospital of Chongqing Medical University, 400016 Chongqing, China. ${ }^{2}$ Department of Health Management Centre (Epidemiology and Biostatistics), First Affiliated Hospital, Army Medical University, 400038 Chongqing, China. ${ }^{3}$ Department of Epidemiology and Health Statistics, School of Public Health and Management, Chongqing Medical University, 400016 Chongqing, China. ${ }^{4}$ Department of Pharmacy, The First Affiliated Hospital of Chongqing Medical University, 400016 Chongqing, China.
Received: 18 April 2021 Accepted: 16 August 2021

Published online: 28 August 2021

\section{References}

1. Cooper DS, Doherty GM, Haugen BR, Kloos RT, Lee SL, Mandel SJ, Mazzaferri EL, Mclver B, Pacini F, Schlumberger M, Sherman SL, Steward DL, Tuttle RM. Revised American thyroid association management guidelines for patients with thyroid nodules and differentiated thyroid cancer. Thyroid.2009;19: $1167-214$.

2. Zhao W, Han C, Shi X, Xiong C, Sun J, Shan Z, Teng W. Prevalence of goiter and thyroid nodules before and after implementation of the universal salt iodization program in mainland China from 1985 to 2014: a systematic review and meta-analysis. Plos One.2014; 9(10):e109549.

3. Song B, Zuo Z, Tan J, Guo J, Teng W, Lu Y, Liu C. Association of thyroid nodules with adiposity: a community-based cross-sectional study in China. Bmc Endocrine Disorders. 2018; 18(1):3.

4. Jiang $H$, Tian $Y$, Yan W, Kong $Y$, Wang $H$, Wang A, Dou J, Liang P, Mu Y. The prevalence of thyroid nodules and an analysis of related lifestyle factors in Beijing communities. International Journal of Environmental Research and Public Health. 2016:13(4):442.

5. Chen Z, Xu W, Huang Y, Jin X, Deng J, Zhu S, Liu H, Zhang S, Yu Y. Associations of noniodized salt and thyroid nodule among the Chinese population: a large cross-sectional study. American Journal of Clinical Nutrition.2013; 98(3):684-692.

6. Fan L, Tan L, Chen Y, Du C, Zhu M, Wang K, Wei H, Wang W, Gao M, Zhang Y, Cui T, Chen W, Shen J, Zhang W. Investigation on the factors that influence the prevalence of thyroid nodules in adults in Tianjin, China. Journal of Trace Elements in Medicine \& Biology. 2018; 50:537-542.

7. Song J, Zou SR, Guo CY, Zang JJ, Zhu ZN, Mi M, Huang HH, Yu HT, Lu X, Ruan Y, Wu F. Prevalence of thyroid nodules and its relationship with iodine status in shanghai: a population-based study. Biomedical \& Environmental Sciences. 2016; 6:398-407.

8. Rosemary W, Farrell S G, Mathis G. Thyroid nodules: diagnosis and management. Med J Aust. 2018; 209(2):92-98.

9. Yin J, Wang C, Shao Q, Qu D, Song Z, Shan P, Zhang T, Xu J, Liang Q, Zhang $S$, Huang J. Relationship between the prevalence of thyroid nodules and metabolic syndrome in the lodine-Adequate Area of Hangzhou, China: A Cross-Sectional and Cohort Study. Int J Endocrinol. 2014:675796.

10. Xu W, Chen Z, Li N, Liu H, Huo L, Huang Y, Jin X, Deng J, Zhu S, Zhang S. Relationship of anthropometric measurements to thyroid nodules in a Chinese Population. BMJ Open. 2015,5(12): e008452.

11. Buscemi S, Massenti FM, Vasto S, Galvano F, Buscemi C, Corleo D, Barile AM, Rosafio G, Rini N, Giordano C. Association of obesity and diabetes with thyroid nodules. Endocrine. Association of obesity and diabetes with thyroid nodules. Endocrine. 2018; 60(2):339-347.

12. Guo H, Sun M, He W, Chen H, Li W, Tang J, Tang W, Lu J, Bi Y, Ning G, Yang $\mathrm{T}$, Duan $Y$. The prevalence of thyroid nodules and its relationship with metabolic parameters in a Chinese community-based population aged over 40 years. Endocrine. 2014; 45:230-235.

13. Zheng L, Yan W, Kong Y, Liang P, Mu Y. An Epidemiological Study of Risk Factors of Thyroid Nodule and Goiter in Chinese Women. International Journal of Environmental Research and Public Health. 2015;12(9): 11608-20.

14. Liu Y, Lin Z, Sheng C, Zhu Y, Huang Y, Zhong N, Jia Z, Qu S. The prevalence of thyroid nodules in northwest China and its correlation with metabolic parameters and uric acid. Oncotarget. 2017:8(25):41555-62.

15. Ma WY, Yang CY, Shih SR, Hsieh HJ, Hung CS, Chiu FC, Lin MS, Liu PH, Hua $\mathrm{CH}$, Hsein YC. Measurement of Waist Circumference: Midabdominal or iliac crest? Diabetes Care. 2013; 36:1660-6.

16. Kwak JY, Han KH, Yoon JH, Moon HJ, Son EJ, Park SH, Jung HK, Choi JS, Kim BM, Kim EK. Thyroid imaging reporting and data system for US features of nodules: a step in establishing better stratification of cancer risk. Radiology. 2011;260(3): 892-899.

17. Zeng MD, Fan JG, Lu LG, Li Y, Chen C, Wang B. Chinese National Consensus Workshop on Nonalcoholic Fatty Liver Disease Guidelines for the diagnosis and treatment of nonalcoholic fatty liver diseases. J Dig Dis. 2008; 9:108-112.

18. Chen C, Lu FC. The guidelines for prevention and control of overweight and obesity in Chinese adults. Biomedical \& Environmental ences Bes.2004; 17 Suppl:1-36

19. Jia WP, Wang C, Jiang S, Pan JM. Characteristics of obesity and its related disorders in China. Biomed Environ Sci. 2010;23:4-11. 
20. Chinese Joint Committee for Developing Chinese Guidelines on Prevention and Treatment of Dyslipidemia in Adults Chinese guidelines. Chinese guidelines on prevention and treatment of dyslipidemia in adults (In Chineses). Zhonghua Xin Xue Guan Bing Za Zhi. 2007; 35:390-419.

21. Alberti KG, Zimmet PZ. Definition, diagnosis and classification of diabetes mellitus and its complications. Part 1: diagnosis and classification of diabetes mellitus provisional report of a WHO consultation. Diabetic medicine: a journal of the British Diabetic Association.1998; 15:539-53.

22. Ezzat S, Sarti DA, Cain DR, Braunstein GD. Thyroid incidentalomas. Prevalence by palpation and ultrasonography. Arch Intern Med. 1994; 154(16):1838-1840

23. Guth S, Theune U, Aberle J, Galach A, Bamberger CM. Very high prevalence of thyroid nodules detected by high frequency $(13 \mathrm{MHz})$ ultrasound examination. European Journal of Clinical Investigation. 2009; 39(8):699-706.

24. Moon JH, Hyun MK, Lee JY, Shim J, Kim TH, Choi HS, Ahn HY, Kim KW, Park DJ, Park YJ, Yi KH. Prevalence of thyroid nodules and their associated clinical parameters: a large-scale, multicenter-based health checkup study. Korean Journal of Internal Medicine. 2018; 33(4): 753-762.

25. Hurtado-López LM, Basurto-Kuba E, Oca-Durán ERMD, Pulido-Cejudo A, Athié-Gutiérrez C. Prevalence of thyroid nodules in the valley of mexico. Cirugia Y Cirujanos. 2011;79(2):114-117.

26. Yang $Y X$, Shi LX. A survey of the prevalence of thyroid nodules in a community-based population in Guiyang (In Chinese). Proceedings of the 10th Annual Meeting of Chinese Society of Endocrinology. 2011; $12: 162-163$

27. Yu X, Fan C, Shan, Z, Teng X, Teng W. A five-year follow-up study of goiter and thyroid nodules in three regions with different iodine intakes in China. Journal of endocrinological investigation. 2008; 31:243-250.

28. Zhao SH, Wang YG, Yan SL, Wang YH, Han L, Wang F, Yu XL. A survey of present status of thyroid goiter and urine iodine status of residents in the coastal regions of Shandong Province (In Chinese). Med J Qilu. 2004; 19: 221-223.

29. Liang Q, Yu S, Chen S, Yang Y, Li D. Association of Changes in Metabolic Syndrome Status With the Incidence of Thyroid Nodules: A Prospective Study in Chinese Adults. Frontiers in Endocrinology. 2020; 11:582.

30. Yang HX, Zhong $Y$, Lv WH, Zhang F, Yu H. Association of adiposity with thyroid nodules: a cross-sectional study of a healthy population in Beijing, China. BMC Endocrine Disorders. 2019; 19:102

31. Zou B, Sun L, Wang X, Chen Z. The Prevalence of Single and Multiple Thyroid Nodules and Its Association with Metabolic Diseases in Chinese: A Cross-Sectional Study. Int J Endocrinol. 2020;2020(5):1-11.

32. Knudsen N, Laurberg P, Perrild H, Bülow I, Ovesen L, Jørgensen T. Risk factors for goiter and thyroid nodules. Thyroid.2002;12(10):879-88.

33. Rosano GMC, Vitale C, Silvestri A, Fini M. The metabolic syndrome in women: implications for therapy. International Journal of Clinical Practice Supplement. 2004; 139:20.

34. Derwahl M, Nicula D. Estrogen and its role in thyroid cancer. Endocr Relat Cancer. 2014;21(5):273-283.

35. Manole D, Schildknecht B, Gosnell B, Adams E, Derwahl M. Estrogen promotes growth of human thyroid tumor cells by different molecular mechanisms. Journal of Clinical Endocrinology \& Metabolism. 2001;86(3):1072.

36. Lopez-Otin C, Blasco MA, Partridge L, Serrano M,Kroemer G. The hallmarks of aging. Cell.2013:153(6):1194-217.

37. Zaki SM, Mohamed EA, Abdel FS, Abdullah H, Kaszubowska L. Ageassociated functional morphology of thyroid and its impact on the expression of vimentin, cytokeratins and VEGF. The role of nigella in refinement. Folia Histochem Cytobiol.2018; 56(3): 159-171.

38. Su Y, Zhang Y L, Zhao M, Zhang HQ, Zhang X, Guan QB,Yu CX, Shao SS, Xu J. Association Between Thyroid Nodules and Volume and Metabolic Syndrome in an lodine-Adequate Area: A Large Community-Based Population Study. Metab Syndr Relat Disord. 2019;17(4):217-222.

39. Kim JY, Jung EJ, Park ST, Jeong SH, Jeong CY, Ju YT, Lee YJ, Hong SC, Choi SK, Ha WS. Body size and thyroid nodules in healthy Korean population. Journal of the Korean Surgical Society. 2012; 82(1):13-17.

40. Vondra K, Vrbikova J, Dvorakova K. Thyroid gland diseases in adult patients with diabetes mellitus. Minerva Endocrinol. 2005;30(4):217-236.

41. Zhu HF, Yang Y, Li JY, Li XM, Ma AG. Prevalence of thyroid nodules and influencing factors among employees of acompany in Qingdao. Zhonghua Yu Fang Yi Xue Za Zhi. 2012; 46(3):228-232.

42. Wang JY, Wang CY, Pei D, Lai CC, Chen YL, Wu CZ, Chang YL, Hsu CH, Pei C, Tang SH. Association between thyroid function and metabolic syndrome in elderly subjects. Journal of the American Geriatrics Society. 2010; 58(8): 1613-1614.

43. Shin J, Kim M H, Yoon K H, Kang Ml, Cha BY, Lim D. Relationship between metabolic syndrome and thyroid nodules in healthy Koreans. Korean J Intern Med.2016;31(1):98-105.

44. Ayturk S, Gursoy A, Kut A, Anil C, Nar A, Tutuncu NB. Metabolic syndrome and its components are associated with increased thyroid volume and nodule prevalence in a mild-to-moderate iodine deficient area. Eur. J. Endocrinol. 2009;161(4):599-605.

45. Rezzonico J, Rezzonico M, Pusiol E, Pitoia F, Niepomniszcze H. Introducing the thyroid gland as another victim of the insulin resistance syndrome. Thyroid. 2008; 18(4):461-464

46. Tsatsoulis A. The Role of Insulin Resistance/Hyperinsulinism on the Rising Trend of Thyroid and Adrenal Nodular Disease in the Current Environment. Journal of Clinical Medicine. 2018; 7(3):37.

47. Jornayvaz FR, Lee HY, Jurczak MJ, Alves TC, Guebre-Egziabher F, Guigni BA, Zhang D, Samuel VT, Silva JE, Shulman Gl. Thyroid hormone receptor-a gene knockout mice are protected from diet-induced hepatic insulin resistance. Endocrinology. 2012; 2:583-91.

\section{Publisher's Note}

Springer Nature remains neutral with regard to jurisdictional claims in published maps and institutional affiliations.
Ready to submit your research? Choose BMC and benefit from:

- fast, convenient online submission

- thorough peer review by experienced researchers in your field

- rapid publication on acceptance

- support for research data, including large and complex data types

- gold Open Access which fosters wider collaboration and increased citations

- maximum visibility for your research: over $100 \mathrm{M}$ website views per year

At $\mathrm{BMC}$, research is always in progress.

Learn more biomedcentral.com/submissions 